\title{
Iron overload and chelation therapy in hemoglobinopathies
}

\author{
Rayan Bou-Fakhredin, Joseph Elias, Ali T. Taher \\ Department of Internal Medicine, American University of Beirut Medical Center, Beirut, Lebanon
}

\begin{abstract}
Iron overload (IOL) is highly prevalent among patients with hemoglobinopathies; both transfusion dependent thalassemia (TDT) and non-transfusion dependent thalassemia (NTDT). Whether IOL is secondary to regular transfusions like in TDT, or develops from increased intestinal absorption like in NTDT, it can cause significant morbidity and mortality. In TDT patients, iron accumulation in organ tissues is highly evident, and leads to organ toxicity and dysfunction. IOL in NTDT patients is cumulative with advancing age, and concern with secondary morbidity starts beyond the age of 10 years, as shown by the OPTIMAL CARE study. Several modalities are available for the diagnosis and monitoring of IOL. Serum ferritin (SF) assessment is widely available and heavily relied on in resource-poor countries. Non-invasive iron monitoring using MRI has become the gold standard to diagnose IOL. Three iron chelators are currently available for the treatment of IOL: deferoxamine (DFO) in subcutaneous or intravenous injection, oral deferiprone (DFP) in tablet or solution form, and oral deferasirox (DFX) in dispersible tablet (DT) and film-coated tablet (FCT). Today, the goal of ICT is to maintain safe levels of body iron at all times. Appropriate tailoring ICT with chelator choices and dose adjustment must be implemented in a timely manner. Clinical decision to initiate, adjust and stop ICT is based on SF, MRI-LIC and cardiac T2*. In this article, we review the mechanism of IOL in both TDT and NTDT, the pathophysiology behind it, its complications, and the different ways to assess and quantify it. We will also discuss the different ICT modalities available, and the emergence of novel therapies.
\end{abstract} Correspondence: Ali T. Taher, Tel.: +961-1-350-000; Fax:+961-1-370-814.
E-mail: ataher@aub.edu.lb

Key words: Iron overload; iron chelation therapy; non-transfusion dependent thalassemia; transfusion dependent thalassemia; liver iron concentration; serum ferritin.

Author contributions: Rayan Bou-Fakhredin and Joseph Elias performed research and wrote the paper. Ali T. Taher critically reviewed the manuscript and supervised the whole work. All authors read and approved the final draft.

Conflicts of interest: Rayan Bou-Fakhredin and Joseph Elias have no conflicts of interest to disclose. Ali T. Taher receives research funding and honoraria from Novartis Pharmaceuticals, and research funding from Celgene and Roche.

This work is licensed under a Creative Commons Attribution 4.0 License (by-nc 4.0).

(C) Copyright R. Bou-Fakhredin et al., 2018

Licensee PAGEPress, Italy

Thalassemia Reports 2018; 8:7478

doi:10.4081/thal.2018.7478

\section{Introduction}

Thalassemia is an inherited disease with multiple genetic forms, including alpha-thalassemia, beta-thalassemia, hemoglobin E/beta thalassemia, and others. Molecular defects in the alpha-globin gene cluster on chromosome 16 or the beta-globin gene cluster on chromosome 11 result in defective hemoglobin synthesis. This in turn leads to an imbalance in the relative quantity of alpha-globin and beta-globin chains [1]. Therefore, the disease hallmarks consist first and foremost of the before mentioned imbalance in the $\alpha / \beta$-globin chain ratio, which in turn leads to the following cascade of events and disease hallmarks including ineffective erythropoiesis, and chronic hemolytic anemia (Figure 1).

Thalassemic disorders lie on a spectrum of severity with different clinical phenotypes, complications, and strategies for treatment. The grade of this severity relies on the significance of the globin gene mutation and coinheritance of other genetic determinants. [2] The degree of transfusion dependence is one of the elements considered in a recent classification of thalassemic disorders into transfusion- dependent thalassemia (TDT) and non-transfusion-dependent thalassemia (NTDT). Iron overload (IOL) is highly prevalent among patients with hemoglobinopathies. Whether IOL is secondary to regular transfusions like in TDT, or develops from increased intestinal absorption like in NTDT, it can cause significant morbidity and mortality. In TDT patients, iron accumulation in organ tissues is highly evident, and leads to organ toxicity and dysfunction. In NTDT patients, IOL is cumulative with advancing age, and concern with secondary morbidity starts beyond the age of 10 years. [1] In this article, we review the mechanism of IOL in both TDT and NTDT, the pathophysiology behind it, its complications, and the different ways to assess and quantify it. We will also be addressing the different ICT modalities available, and discuss the emergence of novel therapies targeting IOL.

\section{Mechanism of iron overload in transfusion dependent thalassemia and non-transfusion dependent thalassemia}

The predominant mechanisms driving the process of iron loading include increased iron burden secondary to transfusion therapy in TDT and enhanced intestinal absorption secondary to ineffective erythropoiesis and hepcidin suppression in NTDT. Different organs are affected differently by iron overload in TDT and NTDT owing to the underlying iron loading mechanism and rate of iron accumulation[1].

Unfortunately, the human body lacks a physiological mechanism for removal of the excess iron load resulting from blood transfusion[3]. Each unit of transfused packed red blood cells contains 200 to $250 \mathrm{mg}$ elemental iron. In TDT, transfusional iron usually amounts to 0.3 to $0.6 \mathrm{mg} / \mathrm{kg}$ per day with an assumed monthly transfusion rate of 2 to $4 \mathrm{U}$ packed red blood cells. Senescent transfused red blood cells are phagocytized by the reticuloendothelial macrophages. This leads to the release of cellular iron into the 
plasma to bind transferring; which is the main iron transport protein and is capable of binding two ${ }^{\mathrm{Fe} 3+}$ Molecules at once. It is only when transferrin binding gets saturated, that we start having iron accumulation: because the now non-transferrin-bound iron (NTBI) is readily transported through calcium channels into the liver (hepatocytes), heart (cardiac myocytes), and endocrine glands. The accumulation of iron in different organs leads to the different clinical complications of IOL $[1,3]$. This accumulation of NTBI in different types of cells leads to its metabolism and the production of reactive oxygen species (ROS) contributing to the cellular dysfunction, apoptosis, and necrosis seen in the target organs[3, 4].

Transferrin carrying 2 molecules of $\mathrm{Fe}^{3+}$ then binds to transferrin receptor 1 (TfR1) and transferrin receptor 2 (TfR2), then gets endocytosed. The acidic environment of the lysosomes, causes the release of $\mathrm{Fe}^{3+}$ from transferrin, and its reduction to $\mathrm{Fe}^{2+}$. $\mathrm{Fe}^{2+}$ then reaches the cytosol through divalent metallic transporter 1[1]. While TfR2 is uniquely expressed in the liver and intestine, TfR 1 is expressed in most tissues, including erythroid precursors, the liver, and the myocardium. The affinity of TfR1 for iron is higher than that of TfR 2 by $\sim 25$ times. Interestingly, TfR 2 lacks an iron responsive element, and iron loading continues to happen in the liver despite high liver iron concentration (LIC), while TfR1 is downregulated with elevated transferrin saturation. Previously, the most important clinical complication of iron overload has been cardiac siderosis, which is at the origin of arrhythmias and heart failure and has been a major cause of mortality in TDT. However, with the advances in IOL diagnosis and management nowadays, cardiac mortality has declined significantly, allowing light to be shed on hepatic and endocrine dysfunction as other complications of IOL in TDT patients[4].

Even in the absence of regular red blood cells transfusions, IOL still develops in patients with NTDT. Remarkably, it has been noted that iron accumulation preferentially occurs in the liver in patients with NTDT and rather than the myocardium. This was established after observational studies showed absence of cardiac siderosis even in patients with severely elevated liver iron content (LIC) [5]. Normally, Hepcidin synthesis by the liver suppresses the release of iron from erythroid precursors, hepatocytes, basolateral membranes of hepatocytes, and macrophages by binding to ferroportin, which

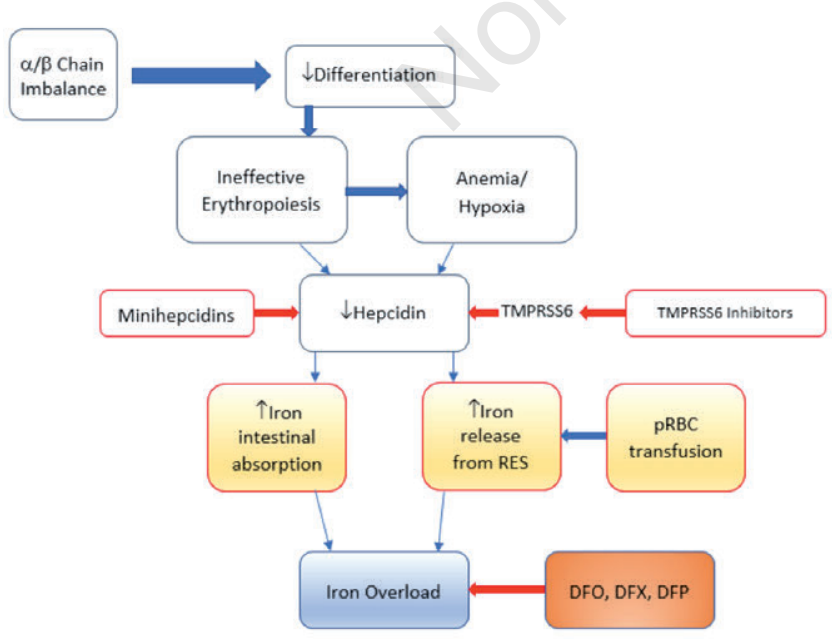

Figure 1. Pathophysiology, mechanism of IOL and novel therapies targeting IOL in $\beta$-Thalassemia. TMPRSS6, transmembrane protease serine 6; DFO, deferoxamine; DFP, deferiprone; DFX, deferasirox. mediates iron export[1]. It is believed that the ineffective erythropoiesis, along with the state of chronic anemia/hypoxia leads to the inappropriately low levels of hepcidin. This in turn contributes to IOL through two mechanisms: increased intestinal iron absorption through lowering ferroportin, and increased release of recycled iron from the reticuloendothelial system. This in turn leads to preferential portal and subsequently hepatocyte iron loading, depletion of macrophage iron, and relatively lower levels of serum ferritin (compared to TDT patients) [6].

\section{Iron overload complications in transfusion dependent thalassemia and non-transfusion dependent thalassemia}

\section{Iron overload complications in transfusion dependent thalassemia}

As previously mentioned, when iron content surpasses transferrin binding capacity and hemosiderin/ferritin storage ability, toxic NTBI enters mitochondria and leads to the formation of toxic radicals and ROS. This in turn leads to gene alterations resulting in cell apoptosis and or fibrosis in different target organs including the myocardium, liver, and endocrine glands [7]. Given the constant need for blood transfusions in TDT, along with hypoxia/anemia induced hepcidin suppression, IOL occurs at a faster rate in TDT patients when compared to NTDT patients. This is also evident in the clinical course of the two diseases, as IOL complications are more pronounced in the TDT group.

a. Cardiac complications - Despite the advances in ICT, cardiovascular disorders remain the leading cause of morbidity in TDT patients, and it remains crucially important for clinicians to recognize it early on as it mandates intensified chelation therapy. IOL related cardiac complications include reversible myocyte injury, arrhythmias including heart block, and arterial changes with loss of vascular compliance [7-9].

b. Hepatic complications - The liver is another organ that is highly susceptible to IOL induced damage in TDT patients. Hepatic macrophages known as Kupffer cells are primarily affected due to their role in $\mathrm{RBC}$ degradation. The intra-macrophagic iron will be released in the bloodstream in a progressive manner. During this process, plasma transferrin gets saturated which leads to the appearance of NTBI. NTBI will in turn target different organs including the heart, liver and endocrine organs. Hence controlling liver iron content is crucial to protect the liver along with the other organ systems [10]. Hepatic complications comprise hepatic fibrosis, cirrhosis, and in cases hepatocellular carcinoma [11].

c. Endocrine and bone complications - Endocrine disorders seen in TDT patients due to IOL include short stature and growth retardation, hypogonadism and delayed puberty, hypothyroidism, impaired glucose tolerance and diabetes mellitus, hypoparathyroidism, adrenal insufficiency as well as osteoporosis $[12,13]$.

\section{Iron overload complications in non-transfusion dependent thalassemia}

NTDT is associated with a high morbidity profile that can start manifesting as early as 10 years of age. Iron burden and accumulation stands behind some of the complications seen in NTDT: by promoting oxidative damage in different organs of the body, and inducing multiple organ dysfunction.

a. Cardiac Disease - Whereas cardiac disease is one of the most important causes of morbidity/mortality in patients with TDT, 
it is manifested in a less severe manner in patients with NTDT. In fact, while IOL in TDT leads to left ventricular (LV) dysfunction, heart failure and in severe cases to cardiogenic shock, cardiac complications in NTDT are related to right sided heart failure secondary to pulmonary hypertension [8]. However, the risk of LV decompensation in patients with NTDT is minimal, but increases with age. This might be explained by the fact that iron deposition in the myocardium happens at a faster rate and is much more common in patients with TDT when compared to patients with NTDT [14]. Moreover, when compared to healthy individuals, patients with NTDT were found to have a higher prevalence of rhythm disorders, pericardial diseases and valvular abnormalities $[8,9]$.

b. Liver Complications - In NTDT, most iron accumulation targets the liver, and patients are at an increased risk of hepatic fibrosis, cirrhosis, and eventually developing hepatocellular carcinoma (HCC). IOL is one of the most important risk factors for hepatic failure and cirrhosis seen in thalassemia patients. Even in the absence of chronic hepatitis C (HCV) infection, NTDT patients are at an increased risk of HCC due to IOL. As already mentioned, iron accumulation is associated with the formation of free radicals and reactive oxygen species (ROS) in different target organs, specifically hepatocytes leading to cellular damage by inflicting damage to tumor suppressor genes and DNA repair genes. Moreover, iron has a profibrogenic effect which in turn accelerates the development of liver cirrhosis $[15,16]$.

c. Endocrinopathies - Iron accumulation can also disrupt the hypothalamic-pituitary axis (HPA), leading to an array of endocrine diseases in thalassemia patients such as hypogonadism, hypothyroidism, hypoparathyroidism, diabetes mellitus, and adrenal insufficiency. Endocrinopathies form an important source of morbidity in NTDT patients, but with a lower prevalence than their counterparts in TDT. This may be attributed to the hepatic dominance of iron loading and to the slower rate at which IOL occurs in patients with NTDT $[17,18]$

d. Kidney disease - Kidneys are also affected by iron overload, manifesting as proteinuria, and glomerular hyperfiltration as a result of glomerular and tubulointerstitial injury. It is important to mention that damage to the glomerulus and the tubulointerstitial systems are not only caused by IOL; the chronic state of anemia and hypoxia play a crucial in this too. End stage kidney disease is a possible outcome of IOL induced renal damage in patients with NTDT $[19,20]$.

e. Bone Disease - Iron overload, splenectomy, low fetal hemoglobin levels and female gender appear to be associated with a higher risk of osteoporosis in NTDT patients [21-23]. On the other hand, ICT and hydroxyurea use were correlated with lower rates of osteoporosis.

\section{Diagnosis and Quantification of iron overload in transfusion dependent thalassemia and non-transfusion dependent thalassemia}

\section{Magnetic resonance imaging}

Given its safety and reliability when compared to the invasive liver biopsy, MRI using T2* (in milliseconds) and R2* imaging techniques are now considered the gold standard for LIC quantification. T2* relaxation refers to decay of transverse magnetization caused by a combination of spin-spin relaxation and magnetic field inhomogeneity[24]. This relaxation occurs faster (shorter $\mathrm{T} 2 *$ in $\mathrm{ms}$ ) with increasing tissue (myocardial, liver...) iron concentrations $[1,24]$.
Moreover, Angelucci et.al demonstrated that LIC estimated from MRI imaging in $\mathrm{mg}$ of iron per gram of liver dw correlates reliably with total body iron stores [10]. Most guidelines now rely on LIC and T2* from MRI to diagnose IOL and adapt ICT [1]. Specific LIC and cardiac T2* thresholds have been associated with morbidity in TDT and NTDT $[11,25]$ :

- In NTDT, LIC values greater than $5 \mathrm{mg} / \mathrm{g}$ dw were associated with increased morbidity.

- In TDT, LIC values greater than $7 \mathrm{mg} / \mathrm{g} \mathrm{dw}$ are used to indicate increased risk for complications related to iron overload, while LIC values $>15 \mathrm{mg} / \mathrm{g}$ were predictive of advanced liver fibrosis, mortality, and increased risk of cardiac disease in TDT [10, 25].

- Cardiac T2* values lower than $10 \mathrm{~ms}$ is highly associated with increased risk of symptomatic heart failure and higher mortality in TDT [26].

- Cardiac T2* values between 10 and $20 \mathrm{~ms}$ were associated with lower left ventricular ejection fraction (LVEF) and a higher risk of arrhythmias in TDT [26].

\section{Serum ferritin assessment}

The unavailability of MRI in the developing countries where Thalassemia is most prevalent (Sub-Saharan Africa, Middle East, India, Mediterranean region, and Southeast Asia), and its high cost form major limitations to its use as a tool to quantify and guide ICT. Therefore, the assessment of serum ferritin values and their correlation with LIC becomes of crucial value. In NTDT for example, cutoffs of $300 \mathrm{ng} / \mathrm{mL}$ and $800 \mathrm{ng} / \mathrm{mL}$ were identified: whereas SF levels lower than $300 \mathrm{ng} / \mathrm{mL}$ indicate absent IOL and SF levels higher than $800 \mathrm{ng} / \mathrm{mL}$ indicate significant IOL [27]. Moreover, results from the ORIENT study revealed that patients with SF $\geq 800 \mu \mathrm{g} / \mathrm{L}$ have a higher incidence of morbidities over 11 years. Based on a ROC analysis, a SF level of $\geq 800 \mu \mathrm{g} / \mathrm{L}$ had the highest accuracy for predicting $\mathrm{LIC} \geq 5 \mathrm{mg} \mathrm{Fe} / \mathrm{g} \mathrm{dw}$. As for the SF values between 300 and 800 , a recent evaluation found that a significant proportion of those NTDT patients had IOL requiring treatment [28]. As for TDT, the cutoff used to initiate ICT is $1000 \mathrm{ng} / \mathrm{mL}$ since SF levels lower than $1000 \mathrm{ng} / \mathrm{mL}$ were associated with lower morbidity and mortality in TDT and this threshold is most commonly use to indicate the need for initiation and as a target for [4, 29]. In a multicenter study conducted in 2017 by Krtittayaphong et al. SF levels had limited ability to correlate with cardiac iron overload in TDT, but were found to predict cardiac siderosis when values were greater than $2500 \mathrm{ng} / \mathrm{mL}$ [30].

\section{SQUID}

LIC can also be derived from the paramagnetism in the liver. This can be measured using superconducting quantum interference device known as SQUID [31]. However, three major drawbacks made SQUID a rarely used technique for LIC measurement: it is costly since it utilizes liquid helium, the apparatus needs to be away from all paramagnetic forces (cars, lifts...) making it impractical, finally it relies on strong mathematical methods and different calibration methods between different devices making the comparison of results between different devices trickier [31].

\section{Iron chelation therapy}

Iron chelation therapy (ICT) is and will always remain the standard method of choice in thalassemia management, decreasing morbidity and mortality in this patient population. The primary goal of ICT today has shifted from treating or rescuing IOL to maintaining safe levels of body iron at all times [32]. Moreover, appropriate tailoring ICT with chelator choices and dose adjust- 
ment must be implemented in a timely manner. The clinical decision to initiate, adjust and stop ICT is based on SF, MRI-LIC and cardiac $\mathrm{T} 2 *$. Three iron chelators are currently available for the treatment of IOL: deferoxamine (DFO) in subcutaneous or intravenous injection; oral deferiprone (DFP) in tablet or solution form; and oral deferasirox (DFX), in dispersible tablet (DT) and-more recently_film-coated tablet (FCT) forms [32-34] (Table 1).

\section{Iron chelation therapy in transfusion dependent thalassemia}

In TDT patients, choices of ICT monotherapy may vary. As first line of treatment the following is recommended: DFO 30-60 $\mathrm{mg} / \mathrm{kg} /$ day, administered over a span of 8-10 hours a day, 5-7 days a week; or DFX $20-40 \mathrm{mg} / \mathrm{kg} /$ day administered once daily [32]. For second line treatment, and when ICT with DFX or DFO is inadequate, DFP is given at a dose of $75-100 \mathrm{mg} / \mathrm{kg} /$ day divided over three doses [32]. Possible combination therapies that have been recommended include DFO+DFP, DFO+DFX and $\mathrm{DFP}+\mathrm{DFX}$ [35-37]. Indications to intensify ICT in TDT: $\mathrm{SF} \geq 2500$ $\mathrm{ng} / \mathrm{mL}$ and/or LIC $>7 \mathrm{mg} / \mathrm{g}$ dry wt. liver and/or cardiac T2 $*<20$ msec. In TDT patients, the indication to stop ICT: SF $<300 \mathrm{ng} / \mathrm{mL}$ and/or LIC $<3 \mathrm{mg} / \mathrm{g}$ dry wt. liver [32] (Table 2).

a. Approach to myocardial IOL - The risk of cardiac dysfunction increases with increasing levels of myocardial iron. High myocardial iron is strongly associated with heart failure and death. Myocardial clearance with ICT occurs at the same time as liver clearance, but is slower in the heart than in the liver. Most prospective studies looking at the efficacy of iron chelators in myocardial iron removal are DFX studies. DFX is the only chelator to have demonstrated efficacy in removing myocardial iron in patients with high baseline LIC.

Results from a 1-year prospective randomized comparison of DFO+DFP combination therapy $v s$ DFO monotherapy conducted on TDT patients with mild to moderate myocardial IOL

Table 1. Characteristics of the currently available iron chelators in thalassemia management [2, 77].

\begin{tabular}{|c|c|c|c|}
\hline & DFO & DFP & DFX \\
\hline Structure & & & \\
\hline $\begin{array}{l}\text { Administration route } \\
\text { Administration time }\end{array}$ & $\begin{array}{l}\text { Subcutaneous orIntravenous } \\
\text { Every 8-12 hours5-7 days/week }\end{array}$ & $\begin{array}{l}\text { Oral (tablets or solution) } \\
3 \text { times daily }\end{array}$ & $\begin{array}{l}\text { Oral (dispersible tablet or film-coated tablet) } \\
\text { Once daily }\end{array}$ \\
\hline $\begin{array}{l}\text { Half-life } \\
\text { Recommended dose }\end{array}$ & $\begin{array}{l}20-30 \text { minutes } \\
30-60 \mathrm{mg} / \mathrm{kg} / \text { day }\end{array}$ & $\begin{array}{l}3-4 \text { hours } \\
75-100 \mathrm{mg} / \mathrm{kg} / \text { day }\end{array}$ & $\begin{array}{l}\text { 12-16 hours } \\
\text { TDT: } 20-40 \text { mg/kg/dayNTDT: } 5-20 \text { mg/kg/day }\end{array}$ \\
\hline $\begin{array}{l}\text { Route of iron excretion } \\
\text { Adverse Events }\end{array}$ & $\begin{array}{l}\text { Urinary and fecal } \\
\text { Delay in bone growth, auditory and } \\
\text { ocular complications, local reactions } \\
\text { and allergies }\end{array}$ & $\begin{array}{l}\text { Urinary } \\
\text { Gastrointestinal complications, } \\
\text { Neutropenia/agranulocytosis, } \\
\text { arthralgia, elevated hepatic enzymes }\end{array}$ & $\begin{array}{l}\text { Fecal } \\
\text { Gastrointestinal bleeding ulceration, and } \\
\text { irritation, elevated hepatic enzymes, increased } \\
\text { creatinine, liver failure and renal insufficiency, } \\
\text { skin rashes }\end{array}$ \\
\hline
\end{tabular}

TDT, Transfusion-dependent thalassemia; NTDT, non-transfusion-dependent thalassemia; DFO, deferoxamine; DFP, deferiprone; DFX, deferasirox.

Table 2. Iron overload characteristics and iron chelation therapy indications in transfusion dependent thalassemia $v s$ non-transfusion dependent thalassemia [78].

\begin{tabular}{|c|c|c|}
\hline & TDT & NTDT \\
\hline Mechanism of IOL & Blood transfusion & Increased intestinal absorption \\
\hline Rate of iron accumulation & Fast & Slow \\
\hline IOL-related complications & $\begin{array}{l}\text { Cardiac siderosis, heart failure and cardiac } \\
\text { arrhythmia, liver fibrosis and cirrhosis, } \\
\text { endocrinopathies }\end{array}$ & $\begin{array}{l}\text { Liver fibrosis, cirrhosis and HCC, endocrinopathies, } \\
\text { proteinuria and glomerular hyperfiltration, thrombosis, PHT, } \\
\text { osteoporosis, osteopenia }\end{array}$ \\
\hline Indication to initiate ICT & $\mathrm{SF} \geq 1000 \mathrm{ng} / \mathrm{mL}$ orLIC $\geq 3 \mathrm{mg} / \mathrm{g}$ dry weight liver & $\mathrm{SF} \geq 800 \mathrm{ng} / \mathrm{mL}$ and/orLIC $\geq 5 \mathrm{mg} / \mathrm{g}$ dry weight liver \\
\hline Indication to intensify ICT & $\begin{array}{l}\mathrm{SF} \geq 2500 \mathrm{ng} / \mathrm{mL} \text { and/or } \\
\mathrm{LIC}>7 \mathrm{mg} / \mathrm{g} \text { dry wt. liver and/or } \\
\text { Cardiac T2* }<20 \mathrm{msec} .\end{array}$ & $\begin{array}{l}\text { LIC after } 6 \text { months of treatment }>7 \mathrm{mg} / \mathrm{g} \text { dry wt. liver or } \\
\text { SF }>1500-2000 \mathrm{ng} / \mathrm{mL}\end{array}$ \\
\hline Indication to stop ICT & $\begin{array}{l}\mathrm{SF}<300 \mathrm{ng} / \mathrm{mL} \text { and/or } \\
\mathrm{LIC}<3 \mathrm{mg} / \mathrm{g} \text { dry wt. liver }\end{array}$ & $\begin{array}{l}\mathrm{SF}<300 \mathrm{ng} / \mathrm{mL} \text { and/or } \\
\mathrm{LIC}<3 \mathrm{mg} / \mathrm{g} \text { dry wt. liver }\end{array}$ \\
\hline Choices of ICT-Monotherapy & $\begin{array}{l}\text { DFO } 30-60 \mathrm{mg} / \mathrm{kg} / \text { day } \\
\text { DFX } 20-40 \mathrm{mg} / \mathrm{kg} / \text { day } \\
\text { DFP } 75-100 \mathrm{mg} / \mathrm{kg} / \text { day }\end{array}$ & DFX 5-20 mg/kg/day \\
\hline Choices of ICT-Combination Therapy & $\begin{array}{l}\mathrm{DFO}+\mathrm{DFP} \\
\mathrm{DFO}+\mathrm{DFX} \\
\mathrm{DFP}+\mathrm{DFX}\end{array}$ & N/A \\
\hline
\end{tabular}

TDT, transfusion-dependent thalassemia; NTDT, non-transfusion dependent thalassemia; SF, serum ferritin; LIC, liver iron concentration; HCC, hepatocellular carcinoma; PHT, pulmonary hypertension; DFO, deferoxamine; DFP, deferiprone; DFX, deferasirox. 
(T2* 8-20 ms) showed that at 12 months, myocardial $\mathrm{T}_{2} *$ improved significantly in both groups [38]. However, the between-group difference was significantly in favor of combination therapy. In comparison with the standard IOL using DFO, combination therapy with DFP showed greater reduction in myocardial iron and improved LVEF [38]. Therefore, combination therapy should be considered in patients whose DFO monotherapy fails to achieve adequate control of myocardial iron [38]. However, addition of DFP to DFO did not always enhance myocardial iron removal in patients with severe myocardial IOL. The cardiac sub study of the EPIC trial, a 1year, multicenter, prospective longitudinal study, looked at the effect of DFX in removing cardiac iron in patients with $\beta$-thalassaemia and myocardial siderosis over 3 years and showed that DFX continually improved myocardial T2* across 3 years irrespective of baseline myocardial iron severity [39]. Different chelators have different strengths in removing NTBI and lowering mitochondrial oxidative stress. Nevertheless, DFX and DFP both improve endothelial function over time [7].

b. Approach to hepatic IOL - With increasing LIC, liver enzymes increase, as well as liver fibrosis. Organ damage and dysfunction can progress [40]. LIC is the best measure of total body iron stores and helps to predict the risk of hepatic and extrahepatic complications $[41,42]$. Effective ICT reduces LIC and may prevent progression of liver disease. LIC levels $>7 \mathrm{mg} / \mathrm{g}$ $\mathrm{dw}$ are associated with increased risk of morbidity and liver disease. LIC levels $>15 \mathrm{mg} / \mathrm{g} \mathrm{dw}$ are associated with increased aminotransferase enzymes concentration, increased risk of hepatic fibrosis and hepatocellular carcinoma (HCC), increased risk of HCC secondary to cirrhosis and increased risk of cardiac disease [40, 42, 43]. DFO therapy has been shown to be associated with a significant decrease in LIC in patients TDT. DFX has also been shown to significantly decrease LIC by 3.1 to $7.8 \mathrm{mg} / \mathrm{g} \mathrm{dw}$ in patients with TDT [44]. One study showed that DFX doses $>30 \mathrm{mg} / \mathrm{kg}$ per day were needed to achieve optimal improvement in LIC in patients with heavy IOL in TDT [45]. DFX monotherapy and DFP monotherapy have been shown to improve hepatic siderosis $[35,46,47]$ However, there is no head-to-head trial comparing DFX and DFP at optimal doses. Based on the most robust data available, we recommend monotherapy with DFX, at a dosage of 20 to $30 \mathrm{mg} / \mathrm{kg}$ or higher per day, or combination therapy with DFO and DFX for the treatment of hepatic siderosis in TDT $[37,44,48]$.I n patients with high LIC, combination therapy of DFX+DFO has been shown to significantly reduce LIC.

c. Approach to IOL in the endocrine organs - Endocrinopathies still account for significant morbidity in TDT [12, 49-51]. For example, pancreatic iron loading (defined as MRI R2* $>100 \mathrm{~Hz}$ ) and severe pituitary iron deposition may possibly develop during the first decade of life $[52,53]$. Intensive combination therapy of DFO and DFP has been associated with prevention and/or reversal of endocrine complications in general [54]. Combined DFP/DFX treatment has also been shown to prevent or reverse endocrine complications in TDT patients. In a recent multicenter retrospective cohort study by Casale $e t$ $a l$, the low prevalence of new endocrine disorders and stabilization of preexisting ones during DFX therapy, suggest that DFX may play a protective in endocrinopathies [55].

\section{Iron chelation therapy in non-transfusion dependent thalassemia}

While all three iron chelators have proven their effectiveness as iron chelators in TDT patients, DFX remains the only drug that has received Food and Drug Administration (FDA) and European
Medicines Agency (EMA) approval for use in NTDT patients, mostly based on results extracted and published from the THALASSA trial $[56,57]$. In this multinational, prospective, randomized, double-blinded phase II trial 1-year DFX treatment of NTDT patients $>10$ years was found to decrease LIC at a daily dose of 5 and $10 \mathrm{mg} / \mathrm{kg}$, respectively, compared to placebo [57]. Sub-analyses further proved DFX 5 and $10 \mathrm{mg} / \mathrm{kg} /$ day starting doses led to consistent reductions in LIC across all patients, irrespective of baseline LIC, SF, underlying NTDT form, splenectomy status or demographics such as age, gender and race [57]. The analyses also showed that greater reductions in LIC were achieved in patients dose-escalated at 6 months from DFX $10 \mathrm{mg} / \mathrm{kg} /$ day starting dose to $20 \mathrm{mg} / \mathrm{kg} /$ day [57]. A 1-year extension phase was then carried out to allow for the assessment of up to 2 years of DFX treatment. Patients continued to respond, with a decrease in LIC and SF over 2 years. Data extracted from the THETIS study [58] further showed that a starting dose of $10 \mathrm{mg} / \mathrm{kg} /$ day of DFX is effective in reducing IOL in NTDT, and that dose escalation up to 30 $\mathrm{mg} / \mathrm{kg} /$ day should be considered starting at week 4 based on LIC response [58]. DFP has not been extensively studied in NTDT. Single-arm, open-label studies with small sample sizes and a more recent randomized controlled trial showed significant decreases in SF and LIC with DFP therapy [59]. DFO has not been systematically studied in NTDT, although studies with small sample sizes and short durations have shown an increase in urinary excretion of iron and a decrease in SF.

In NTDT, specific indications have been established for the initiation, dose escalation and termination of ICT. DFX chelation with initial starting dose of $10 \mathrm{mg} / \mathrm{kg} / \mathrm{day}$ should be started in patients $\geq 10$ years of age (15 years of age in hemoglobin $\mathrm{H}$ disease) if their LIC $\geq 5 \mathrm{mg} \mathrm{Fe} / \mathrm{g}$ dry weight, or if their SF concentration was found to be $\geq 800 \mu \mathrm{g} / \mathrm{L}$ when LIC is not available due to lack of the necessary MRI technology [33]. As for monitoring of iron levels, LIC should be repeated 6 months after therapy initiation, with follow up every 6-12 months, in addition to SF levels being measured every 3 months [33]. If at 6 months LIC is still $>7$ $\mathrm{mg} \mathrm{Fe} / \mathrm{g}$ dry weight (or SF $>1500 \mu \mathrm{g} / \mathrm{L}$ only if LIC is unavailable) with less than $15 \%$ reduction in baseline values, dose escalation should be considered up to $20 \mathrm{mg} / \mathrm{kg} /$ day [33]. DFX therapy can be safely discontinued when patients reach an LIC value of $3 \mathrm{mg}$ $\mathrm{Fe} / \mathrm{g}$ dry weight (or SF level of $300 \mu \mathrm{g} / \mathrm{L}$ only if LIC is unavailable) [33]. In NTDT, it is recommended to intensify ICT if the LIC after 6 months of treatment $>7 \mathrm{mg} / \mathrm{g} \mathrm{dw}$. liver or SF $>1500-2000$ $\mathrm{ng} / \mathrm{mL}$ and $<15 \%$ decrease from baseline. Indications to stop ICT in NTDT include a SF $<300 \mathrm{ng} / \mathrm{mL}$ and/or LIC $<3 \mathrm{mg} / \mathrm{g}$ dry wt. liver (Table 2).

\section{Adherence and advances in iron chelation therapy}

Compliance with ICT is associated with effective control of IOL and improved patient survival [60, 61]. Moreover, adherence to long-term ICT is crucial in preventing IOL-related complications. For example, barriers to optimal adherence to DFX-DT include preparation time, palatability, the need to take the drug in a fasting state, and drug-related side effects, notably gastrointestinal (GI) tolerability [62]. A new FCT formulation was developed, which is swallowed once-daily, whole or crushed, with or without a light meal [62]. The open-label, phase II ECLIPSE study evaluated the overall safety, as measured by the frequency and severity of adverse events (AEs) and changes in laboratory values, in patients treated with DFX-FCT or DFX- DT. Overall incidence of AEs was similar between treatments, but there were fewer serious adverse events (SAEs) with FCT. The study also evaluated patientreported outcomes (PRO) in TDT or lower-risk myelodysplastic 
syndromes patients randomized to receive DFX DT or FCT over a 24-week period [62]. FCT recipients consistently reported better adherence, greater satisfaction, and fewer concerns, with a safety profile consistent with the known DT formulation. These findings suggest a preference in favor of the new formulation, with better patient satisfaction and adherence translating into reduced IOLrelated complications.

\section{Iron chelation therapy in special populations: Pediatric population}

Pediatric TDT patients require adequate blood transfusions for normal growth and skeletal development. The goals of blood transfusion therapy in children with TDT include correction of anemia, suppression of erythroid expansion and bone changes, prevention of spleen enlargement and hypersplenism and ensure appropriate growth and development. TDT patients may have liver IOL as young as age 2 years. Young TDT patients may also have myocardial IOL [63]. Guidelines for pediatric patients include maintaining an average $\mathrm{Hb}$ of $12 \mathrm{~g} / \mathrm{dL}$, max $14 \mathrm{~g} / \mathrm{dL}$, a pre-transfusion $\mathrm{Hb}$ of 9-10.5 $\mathrm{g} / \mathrm{dL}$, and transfusing $\mathrm{pRBC}$ units only: starting with low transfusion frequency in young patients and increase as they grow. Chelation strategies initiated timely and adjusted appropriately in children must be warranted to prevent permanent organ damage that might lead to significant morbidity later in life [64]. DFO has been shown to reduce serum ferritin in children with IOL [64]. However, high DFO doses in pediatric patients with low serum ferritin may result in growth failure, which should be distinguished from growth retardation secondary to inadequate transfusion or IOL [65]. In such cases, close monitoring of growth rate, DFO dose/regimen is recommended. Dose reduction was also found to restore growth rate to pre-treatment levels in some cases. Therefore, it is recommended to check on body weight and height every 3 months in children [32]. The experience in DFP is the most limited, with studies available showing it may not be as effective to reduce iron in young children [66]. DFX therapy has been shown to have a long-term efficacy in TDT patients as young as 2 years of age, with no observed negative effects on growth or sexual development [67]. It is important to mention that challenges in the treatment of thalassemia change with age. In early childhood, the clinician must ensure adequate support and therapy to optimize growth and development. In late childhood and adolescence, sexual development and transition of care are important areas of focus. As patients transition in to adulthood, the goals of therapy include preventing long-term complications related to anemia, IOL, and hypercoagulability [68].

\section{Novel therapies targeting iron overload}

Newly emerging therapies targeting iron dysregulation include minihepcidins, and transmembrane protease serine 6 (TMPRSS6) (Figure 1).

\section{Minihepcidins}

Minihepcidins, or long-acting hepcidin analogs, have been shown to restrict iron absorption, and their utilization has shown beneficial effects on ineffective erythropoiesis and consequently IOL [69-71]. These long acting hepcidin analogs have shown to increase the levels of endogenous hepcidin, thus decreasing iron absorption from the GI tract, and increasing the redistribution of iron, thereby limiting end-organ toxicity [72]. Studies conducted on mice have also shown that minihepcidin therapy can increase $\mathrm{Hb}$ concentrations, and also decrease reticulocyte counts in addition to reducing spleen size $[72,73]$.

\section{TMPRSS6}

Several studies have been reported on the use of transmembrane protease serine 6 (TMPRSS6) as an approach to stimulate endogenous hepcidin production [74-76]. TMPRSS6, a transmembrane serine protease, acts by reducing the production of hepcidin. Thus, endogenous hepcidin production can be stimulated by reducing the expression of TMPRSS6. Through data from mouse models, it has been shown that TMPRSS6 gene deletion not only improves anaemia but also reduces ineffective erythropoiesis, splenomegaly, and IOL [74]. Other studies have shown that the use of antisense oligonucleotides or small interfering RNAs that target TMPRSS6 lead to improvements in anaemia and IOL $[75,76]$ Genetic ablation of TMPRSS6 also improved ineffective erythropoiesis and decreased splenomegaly in NTDT patients, without a concomitant decrease in erythropoietin production [74].

\section{Conclusions}

In conclusion, IOL represents an important clinical problem in thalassemia patients. Adequate assessment and monitoring of IOL in TDT and NTDT patients, in addition to tailored ICT, is crucial for preventing the complications known to be associated with this increased iron burden. New treatment modalities are currently being investigated to broaden options available for TDT and NTDT management, with ultimate goals of prolonging longevity, promoting greater compliance and better adherence and improving quality of life. Since both TDT and NTDT patients present with multiple pathophysiologies, tailoring treatment will always remain essential.

\section{References}

1. Taher AT, Saliba AN. Iron overload in thalassemia: different organs at different rates. Hematology Am Soc Hematol Educ Program. 2017;2017(1):265-71.

2. Taher AT, Weatherall DJ, Cappellini MD. Thalassaemia. Lancet. 2017.

3. Saliba A, Taher A. Iron overload in transfusion-dependent thalassemia. Hematology (Amsterdam, Netherlands). 2015;20(5): 311-2.

4. In: rd, Cappellini MD, Cohen A, Porter J, Taher A, Viprakasit $\mathrm{V}$, editors. Guidelines for the Management of Transfusion Dependent Thalassaemia (TDT). Nicosia (CY): Thalassaemia International Federation (c) 2014 Thalassaemia International Federation.; 2014.

5. Taher AT, Musallam KM, Wood JC, Cappellini MD. Magnetic resonance evaluation of hepatic and myocardial iron deposition in transfusion-independent thalassemia intermedia compared to regularly transfused thalassemia major patients. American journal of hematology. 2010;85(4):288-90.

6. Origa R, Galanello R, Ganz T, Giagu N, Maccioni L, Faa G, et al. Liver iron concentrations and urinary hepcidin in beta-thalassemia. Haematologica. 2007;92(5):583-8.

7. Auger D, Pennell DJ. Cardiac complications in thalassemia major. Annals of the New York Academy of Sciences. 2016; 1368(1):56-64.

8. Aessopos A, Farmakis D, Deftereos S, Tsironi M, Tassiopoulos $\mathrm{S}$, Moyssakis I, et al. Thalassemia heart disease: a comparative evaluation of thalassemia major and thalassemia intermedia. Chest. 2005;127(5):1523-30.

9. Amoozgar H, Zeighami S, Haghpanah S, Karimi M. A comparison of heart function and arrhythmia in clinically asymptomatic patients with beta thalassemia intermedia and beta tha- 
lassemia major. Hematology (Amsterdam, Netherlands). 2017;22(1):25-9.

10. Angelucci E, Brittenham GM, McLaren CE, Ripalti M, Baronciani D, Giardini C, et al. Hepatic iron concentration and total body iron stores in thalassemia major. $N$ Engl $\mathrm{J} \mathrm{Med}$. 2000;343(5):327-31.

11. Borgna-Pignatti C, Vergine G, Lombardo T, Cappellini MD, Cianciulli P, Maggio A, et al. Hepatocellular carcinoma in the thalassaemia syndromes. British journal of haematology. 2004;124(1):114-7.

12. Toumba M, Sergis A, Kanaris C, Skordis N. Endocrine complications in patients with Thalassaemia Major. Pediatr Endocrinol Rev. 2007;5(2):642-8.

13. Toumba M, Skordis N. Osteoporosis syndrome in thalassaemia major: an overview. Journal of osteoporosis. 2010;2010: 537673.

14. Taher AT, Musallam KM, El-Beshlawy A, Karimi M, Daar S, Belhoul K, et al. Age-related complications in treatment-naive patients with thalassaemia intermedia. $\mathrm{Br} J$ Haematol. 2010;150(4):486-9.

15. Kew MC. Hepatic iron overload and hepatocellular carcinoma. Cancer letters. 2009;286(1):38-43.

16. Kowdley KV. Iron, hemochromatosis, and hepatocellular carcinoma. Gastroenterology. 2004;127(5 Suppl 1):S79-86.

17. Baldini M, Marcon A, Cassin R, Ulivieri FM, Spinelli D, Cappellini MD, et al. Beta-thalassaemia intermedia: evaluation of endocrine and bone complications. Biomed Res Int. 2014;2014:174581.

18. Cappellini MD, Porter J, El-Beshlawy A, Li CK, Seymour JF, Elalfy $\mathrm{M}$, et al. Tailoring iron chelation by iron intake and serum ferritin: the prospective EPIC study of deferasirox in 1744 patients with transfusion-dependent anemias. Haematologica. 2010;95(4):557-66

19. Brenner BM, Lawler EV, Mackenzie HS. The hyperfiltration theory: a paradigm shift in nephrology. Kidney international. 1996;49(6):1774-7.

20. Mallat NS, Musallam KM, Mallat SG, Ziyadeh FN, Koussa S, Taher AT. End stage renal disease in six patients with beta-thalassemia intermedia. Blood cells, molecules \& diseases. 2013;51(3):146-8.

21. Musallam KM, Cappellini MD, Wood JC, Motta I, Graziadei $\mathrm{G}$, Tamim H, et al. Elevated liver iron concentration is a marker of increased morbidity in patients with beta thalassemia intermedia. Haematologica. 2011;96(11):1605-12.

22. Musallam KM, Taher AT, Cappellini MD, Sankaran VG. Clinical experience with fetal hemoglobin induction therapy in patients with beta-thalassemia. Blood. 2013;121(12):2199212; quiz 372.

23. Taher AT, Musallam KM, Karimi M, El-Beshlawy A, Belhoul $\mathrm{K}$, Daar $\mathrm{S}$, et al. Overview on practices in thalassemia intermedia management aiming for lowering complication rates across a region of endemicity: the OPTIMAL CARE study. Blood. 2010;115(10):1886-92.

24. Chavhan GB, Babyn PS, Thomas B, Shroff MM, Haacke EM. Principles, techniques, and applications of $\mathrm{T} 2 *$-based MR imaging and its special applications. Radiographics : a review publication of the Radiological Society of North America, Inc. 2009;29(5):1433-49.

25. Telfer PT, Prestcott E, Holden S, Walker M, Hoffbrand AV, Wonke B. Hepatic iron concentration combined with long-term monitoring of serum ferritin to predict complications of iron overload in thalassaemia major. British journal of haematology. 2000;110(4):971-7.

26. Carpenter JP, Roughton M, Pennell DJ. International survey of
T2* cardiovascular magnetic resonance in beta-thalassemia major. Haematologica. 2013;98(9):1368-74.

27. Taher AT, Porter J, Viprakasit V, Kattamis A, Chuncharunee S, Sutcharitchan $\mathrm{P}$, et al. Deferasirox reduces iron overload significantly in nontransfusion-dependent thalassemia: 1-year results from a prospective, randomized, double-blind, placebocontrolled study. Blood. 2012;120(5):970-7.

28. Saliba AN, Musallam KM, Cappellini MD, Graziadei G, Daar S, Viprakasit V, et al. Serum ferritin values between 300 and 800 $\mathrm{ng} / \mathrm{mL}$ in nontransfusion-dependent thalassemia: A probability curve to guide clinical decision making when MRI is unavailable. American journal of hematology. 2017;92(3):E35-e7.

29. Borgna-Pignatti C, Rugolotto S, De Stefano P, Zhao H, Cappellini MD, Del Vecchio GC, et al. Survival and complications in patients with thalassemia major treated with transfusion and deferoxamine. Haematologica. 2004;89(10):1187-93.

30. Krittayaphong R, Viprakasit V, Saiviroonporn P, Wangworatrakul W, Wood JC. Serum ferritin in the diagnosis of cardiac and liver iron overload in thalassaemia patients realworld practice: a multicentre study. Br J Haematol. 2017.

31. Fischer R, Piga A, Harmatz P, Nielsen P. Monitoring long-term efficacy of iron chelation treatment with biomagnetic liver susceptometry. Annals of the New York Academy of Sciences. 2005; 1054:350-7.

32. Cappellini M-D, Cohen A, Porter J, Taher A, Viprakasit V. Guidelines for the management of transfusion dependent thalassaemia (TDT). TIF publication. 2014(20).

33. Taher A, Vichinsky E, Musallam K, Cappellini M-D, Viprakasit V. Guidelines for the management of non transfusion dependent thalassaemia (NTDT): Thalassaemia International Federation, Nicosia, Cyprus; 2013.

34. Cappellini MD, Cohen A, Piga A, Bejaoui M, Perrotta S, Agaoglu L, et al. A phase 3 study of deferasirox (ICL670), a once-daily oral iron chelator, in patients with beta-thalassemia. Blood. 2006;107(9):3455-62.

35. Aydinok Y, Ulger Z, Nart D, Terzi A, Cetiner N, Ellis G, et al. A randomized controlled 1-year study of daily deferiprone plus twice weekly desferrioxamine compared with daily deferiprone monotherapy in patients with thalassemia major. Haematologica. 2007;92(12):1599-606.

36. Tanner MA, Galanello R, Dessi C, Smith GC, Westwood MA, Agus A, et al. A randomized, placebo-controlled, double-blind trial of the effect of combined therapy with deferoxamine and deferiprone on myocardial iron in thalassemia major using cardiovascular magnetic resonance. Circulation. 2007;115(14): 1876-84.

37. Aydinok Y, Kattamis A, Cappellini MD, El-Beshlawy A, Origa $\mathrm{R}$, Elalfy $\mathrm{M}$, et al. Effects of deferasirox-deferoxamine on myocardial and liver iron in patients with severe transfusional iron overload. Blood. 2015;125(25):3868-77.

38. Tanner M, Galanello R, Dessi C, Smith G, Westwood M, Agus A, et al. A randomized, placebo-controlled, double-blind trial of the effect of combined therapy with deferoxamine and deferiprone on myocardial iron in thalassemia major using cardiovascular magnetic resonance. Circulation. 2007;115(14):1876-84.

39. Pennell DJ, Porter JB, Cappellini MD, Chan LL, El-Beshlawy A, Aydinok Y, et al. Deferasirox for up to 3 years leads to continued improvement of myocardial $\mathrm{T} 2 *$ in patients with $\beta$-thalassemia major. Haematologica. 2012;97(6):842-8.

40. Jensen PD, Jensen FT, Christensen T, Nielsen JL, Ellegaard J. Relationship between hepatocellular injury and transfusional iron overload prior to and during iron chelation with desferrioxamine: a study in adult patients with acquired anemias. Blood. 2003;101(1):91-6. 
41. Angelucci E, Brittenham GM, Mclaren CE, Ripalti M, Baronciani D, Giardini C, et al. Hepatic iron concentration and total body iron stores in thalassemia major. New Engl J Med. 2000;343(5):327-31.

42. Angelucci E, Muretto P, Nicolucci A, Baronciani D, Erer B, Gaziev J, et al. Effects of iron overload and hepatitis $\mathrm{C}$ virus positivity in determining progression of liver fibrosis in thalassemia following bone marrow transplantation. Blood. 2002;100(1):17-21.

43. Borgna-Pignatti C, Vergine G, Lombardo T, Cappellini MD, Cianciulli P, Maggio A, et al. Hepatocellular carcinoma in the thalassaemia syndromes. Brit J Haematol. 2004;124(1):114-7.

44. Cappellini MD, Bejaoui M, Agaoglu L, Canatan D, Capra M, Cohen A, et al. Iron chelation with deferasirox in adult and pediatric patients with thalassemia major: efficacy and safety during 5 years' follow-up. Blood. 2011;118(4):884-93.

45. Musallam KM, Beydoun A, Hourani R, Nasreddine W, Raad $\mathrm{R}$, Koussa $\mathrm{S}$, et al. Brain magnetic resonance angiography in splenectomized adults with beta-thalassemia intermedia. Eur J Haematol. 2011;87(6):539-46.

46. Pennell DJ, Porter JB, Cappellini MD, El-Beshlawy A, Chan LL, Aydinok Y, et al. Efficacy of deferasirox in reducing and preventing cardiac iron overload in beta-thalassemia. Blood. 2010;115(12):2364-71.

47. Kolnagou A, Kontoghiorghe CN, Kontoghiorghes GJ. Prevention of Iron Overload and Long Term Maintenance of Normal Iron Stores in Thalassaemia Major Patients using Deferiprone or Deferiprone Deferoxamine Combination. Drug Res (Stuttg). 2017;67(7):404-11.

48. Porter JB, Elalfy MS, Taher AT, Aydinok Y, Chan LL, Lee SH, et al. Efficacy and safety of deferasirox at low and high iron burdens: results from the EPIC magnetic resonance imaging substudy. Ann Hematol. 2013;92(2):211-9.

49. De Sanctis V, Elsedfy H, Soliman AT, Elhakim IZ, Soliman NA, Elalaily R, et al. Endocrine profile of beta-thalassemia major patients followed from childhood to advanced adulthood in a tertiary care center. Indian J Endocrinol Metab. 2016;20 (4):451-9.

50. Fung EB, Harmatz PR, Lee PD, Milet M, Bellevue R, Jeng $\mathrm{MR}$, et al. Increased prevalence of iron-overload associated endocrinopathy in thalassaemia versus sickle-cell disease. $\mathrm{Br} J$ Haematol. 2006;135(4):574-82.

51. Gamberini MR, De Sanctis V, Gilli G. Hypogonadism, diabetes mellitus, hypothyroidism, hypoparathyroidism: incidence and prevalence related to iron overload and chelation therapy in patients with thalassaemia major followed from 1980 to 2007 in the Ferrara Centre. Pediatr Endocrinol Rev. 2008;6 Suppl 1:158-69.

52. Noetzli LJ, Panigrahy A, Mittelman SD, Hyderi A, Dongelyan A, Coates TD, et al. Pituitary iron and volume predict hypogonadism in transfusional iron overload. Am J Hematol. 2012; 87(2):167-71.

53. Berdoukas V, Nord A, Carson S, Puliyel M, Hofstra T, Wood J, et al. Tissue iron evaluation in chronically transfused children shows significant levels of iron loading at a very young age. Am J Hematol. 2013;88(11):E283-5.

54. Farmaki K, Tzoumari I, Pappa C, Chouliaras G, Berdoukas V. Normalisation of total body iron load with very intensive combined chelation reverses cardiac and endocrine complications of thalassaemia major. Br J Haematol. 2010;148(3):466-75.

55. Casale M, Citarella S, Filosa A, De Michele E, Palmieri F, Ragozzino A, et al. Endocrine function and bone disease during long-term chelation therapy with deferasirox in patients with beta-thalassemia major. Am J Hematol. 2014;89(12):1102-6.
56. Musallam KM, Rivella S, Vichinsky E, Rachmilewitz EA. Non-transfusion-dependent thalassemias. Haematologica. 2013;98(6):833-44.

57. Taher AT, Porter JB, Viprakasit V, Kattamis A, Chuncharunee $\mathrm{S}$, Sutcharitchan $\mathrm{P}$, et al. Deferasirox effectively reduces iron overload in non-transfusion-dependent thalassemia (NTDT) patients: 1-year extension results from the THALASSA study. Ann Hematol. 2013;92(11):1485-93.

58. Taher AT, Cappellini MD, Aydinok Y, Porter JB, Karakas Z, Viprakasit $\mathrm{V}$, et al. Optimising iron chelation therapy with deferasirox for non-transfusion-dependent thalassaemia patients: 1-year results from the THETIS study. Blood Cells Mol Dis. 2016;57:23-9.

59. Calvaruso G, Vitrano A, Di Maggio R, Lai E, Colletta G, Quota A, et al. Deferiprone versus deferoxamine in thalassemia intermedia: Results from a 5-year long-term Italian multicenter randomized clinical trial. Am J Hematol. 2015;90 (7):634-8.

60. Delea TE, Edelsberg J, Sofrygin O, Thomas SK, Baladi JF, Phatak PD, et al. Consequences and costs of noncompliance with iron chelation therapy in patients with transfusion-dependent thalassemia: a literature review. Transfusion. 2007;47(10):1919-29.

61. Gabutti V, Piga A. Results of long-term iron-chelating therapy. Acta Haematol. 1996;95(1):26-36.

62. Taher AT, Origa R, Perrotta S, Kourakli A, Ruffo GB, Kattamis A, et al. New film-coated tablet formulation of deferasirox is well tolerated in patients with thalassemia or lower-risk MDS: Results of the randomized, phase II ECLIPSE study. Am J Hematol. 2017;92(5):420-8.

63. Wood JC, Origa R, Agus A, Matta G, Coates TD, Galanello R. Onset of cardiac iron loading in pediatric patients with thalassemia major. Haematologica. 2008;93(6):917-20.

64. Musallam K, Cappellini MD, Taher A. Challenges associated with prolonged survival of patients with thalassemia: transitioning from childhood to adulthood. Pediatrics. 2008;121(5): e1426-e9.

65. Olivieri NF, Koren G, Harris J, Khattak S, Freedman MH, Templeton DM, et al. Growth failure and bony changes induced by deferoxamine. Am J Pediatr Hematol Oncol. 1992; 14(1):48-56.

66. Viprakasit V, Nuchprayoon I, Chuansumrit A, Torcharus K, Pongtanakul B, Laothamatas J, et al. Deferiprone (GPO-LONE®) monotherapy reduces iron overload in transfusiondependent thalassemias: 1-year results from a multicenter prospective, single arm, open label, dose escalating phase III pediatric study (GPO-L-ONE; A001) from Thailand. American journal of hematology. 2013;88(4):251-60.

67. Cappellini MD, Bejaoui M, Agaoglu L, Canatan D, Capra M, Cohen A, et al. Iron chelation with deferasirox in adult and pediatric patients with thalassemia major: efficacy and safety during 5 years9 follow-up. Blood. 2011;118(4):884-93.

68. Musallam K, Cappellini MD, Taher A. Challenges associated with prolonged survival of patients with thalassemia: transitioning from childhood to adulthood. Pediatrics. 2008;121(5): e1426-9.

69. Casu C, Oikonomidau R, Shah Y, Nemeth E, Ganz T, MacDonald B, et al. Concurrent treatment with minhepcidin and deferiprone improves anemia and enhances reduction of spleen iron in a mouse model of non-transfusion dependent thalassemia. Am Soc Hematology; 2014.

70. Goldberg A, Nemeth E, Ganz T, Gardenghi S, MacDonald B, Rivella S. Treatment with minihepcidin peptide improves anemia and iron overload in a mouse model of thalassemia intermedia. Am Soc Hematology; 2013. 
71. Preza GC, Ruchala P, Pinon R, Ramos E, Qiao B, Peralta MA, et al. Minihepcidins are rationally designed small peptides that mimic hepcidin activity in mice and may be useful for the treatment of iron overload. The Journal of clinical investigation. 2011;121(12):4880.

72. Gardenghi S, Ramos P, Marongiu MF, Melchiori L, Breda L, Guy E, et al. Hepcidin as a therapeutic tool to limit iron overload and improve anemia in $\beta$-thalassemic mice. The Journal of clinical investigation. 2010;120(12):4466.

73. Ramos E, Ruchala P, Goodnough JB, Kautz L, Preza GC, Nemeth E, et al. Minihepcidins prevent iron overload in a hepcidin-deficient mouse model of severe hemochromatosis. Blood. 2012;120(18):3829-36.

74. Nai A, Pagani A, Mandelli G, Lidonnici MR, Silvestri L, Ferrari G, et al. Deletion of TMPRSS6 attenuates the pheno- type in a mouse model of beta-thalassemia. Blood. 2012;119(21):5021-9.

75. Guo S, Casu C, Gardenghi S, Booten S, Aghajan M, Peralta R, et al. Reducing TMPRSS6 ameliorates hemochromatosis and beta-thalassemia in mice. J Clin Invest. 2013;123(4):1531-41.

76. Schmidt PJ, Toudjarska I, Sendamarai AK, Racie T, Milstein S, Bettencourt BR, et al. An RNAi therapeutic targeting Tmprss6 decreases iron overload in $\mathrm{Hfe}(-/-)$ mice and ameliorates anemia and iron overload in murine beta-thalassemia intermedia. Blood. 2013;121(7):1200-8.

77. Ben Salah N, Bou-Fakhredin R, Mellouli F, Taher AT. Revisiting beta thalassemia intermedia: past, present, and future prospects. Hematology. 2017;22(10):607-16.

78. Taher AT, Weatherall DJ, Cappellini MD. Thalassaemia Lancet. 2018;391(10116):155-67. 